\title{
Occurrence of oral health beliefs and misconceptions among Indian population
}

\begin{abstract}
Objective: The aim of the present study was to explore cultural beliefs and taboos regarding dentistry among Indian population.

Methods: In this cross-sectional study 1664 subjects aged 18 years and above were randomly selected using multistage cluster sampling and surveyed using a self administered structured questionnaire including 16 dichotomous questions pre-tested through a pilot survey. The Student's T-test and ANOVA test were used as test of significance.

Results: The study revealed that people have cultural beliefs and taboos regarding dentistry. The deficit was greater in the rural areas in all aspects. There was statistically significant difference according to sex with females having lower mean scores as they were more involved in taboos. In addition, a positive linear correlation was found between educational level and cultural beliefs \& taboos in dentistry (Pearson's correlation, $\mathrm{r}=0.537, \mathrm{P}=0.01$ ).

Conclusion: Overall more than half of the participants lack awareness particularly in rural areas; they still believe in old unscientific tales, and illiteracy is also an important factor responsible for this.
\end{abstract}

Keywords: beliefs, oral health, taboos, ancient cultures, civilizations, customs, cultural mores, habits, population
Volume I Issue 5 - 2014

Sumit Kochhar,' Karanprakash Singh, ${ }^{2}$ Pinaka Pani, ${ }^{2}$ RamanPreet Kaur Bhullar, ${ }^{2}$ Amandeep Bhullar, ${ }^{2}$ Chitra Anandani ${ }^{3}$

'MDS, Guru Nanak Dev Dental College \& Research Institute, India

2MDS, Genesis Institute of Dental Sciences and Research, India ${ }^{3} \mathrm{MDS}$, Smile dental care, Ferozepur, India

Correspondence: Sumit Kochhar, MDS, Guru Nanak Dev Dental College \& Research Institute, Sunam, Punjab, India, Email drkarankahlon@gmail.com

Received: September 29, 2014 | Published: October 06, 2014

\section{Introduction}

Health cannot be isolated from its social context. The social and economic factors have as much influence on health as medical interventions. ${ }^{1}$ In ancient times health and illness were interpreted in a cosmological and anthropological perspective. Medicine was dominated by magical and religious beliefs, which were an integral part of ancient cultures and civilizations. ${ }^{2}$

Due to the lack of knowledge, the primitive man attributed disease and, in fact, all human sufferings and other calamities to the wrath of Gods, such as the invasion of body by "evil spirits". The concept of disease in which ancient man believed is known as the "supernatural theory of disease". ${ }^{3}$ All people, whether rural or urban, have their own beliefs and practices concerning health and disease ${ }^{4}$. This diversity equally applies to oral diseases and treatments. Since time immemorial the teeth, the mouth, and the face have held seemingly intrinsic fascination for mankind..$^{5}$ They have been and continue to be the subject of many customs, cultural mores, habits, beliefs, superstitions and taboos.

A taboo is a strong social prohibition (urban) relating to any area of human activity or social custom that is sacred and forbidden based on moral judgment and religious beliefs. ${ }^{6}$ Cultural taboos or beliefs have influenced the population since long. ${ }^{7}$ These negative traditions and behaviours are harmful to social welfare. ${ }^{8}$

Gradually with the development of education, these taboos and beliefs are disappearing, but still they persist and are commonly encountered. The field of dentistry is not exceptional to these cultural beliefs. Regarding tooth and tooth ache there have been various superstitions; the popular ones are described in this study. Traditional Indian beliefs and taboos were found to correlate inversely with preventive dental health behaviour in the population. ${ }^{9}$

Thus the purpose of the present survey was to ascertain the current prevalence of these cultural taboos and beliefs regarding dentistry among the Indian population. The intent is that this assessment will be helpful in shaping the future health programs and creating dental awareness.

\section{Materials and methods}

This cross-sectional survey was conducted in November 2012 at Tehsil Sunam, of district Sangrur, Punjab province, India. The total population of the Sunam is 165000 with $70 \%$ living in rural settings, and the majority of the population relying on agriculture for subsistence.

By multi-stage cluster sampling, four urban sites were selected in the city and four villages were picked randomly from the list of all the villages in the Tehsil. In the urban areas, data were collected from all sources such as factories, offices, hospitals, and main market areas by the investigator. For rural areas, all the households in the village were visited for selecting the sample population. In each of the selected household all the people who were above 18 years of age and were willing to participate were included in the study after taking informed consent. 
Before commencement of the survey, ethical approval was obtained from the Ethical Committee, and official permission was received from Guru Nanak Dev Dental College, Sunam. This study sample comprised 1664 subjects including 706 urban (42.4\%) and 958 rural participants (57.6\%). A self-administered, structured questionnaire written in Punjabi including 16 items was designed to evaluate cultural beliefs and taboos regarding oral health care. The survey questionnaire was reviewed and tested among fifty participants in order to ensure the reliability and validity of the questionnaire. The questionnaire was modified based on the results of the pilot study. Examples of information that was gathered includes: personal sociodemographic characteristics, extraction of upper teeth and its effect on eye sight, worms in the teeth as shown by unqualified doctors, loosening of teeth after oral prophylaxis, neonatal teeth being dangerous for grandparents, spacing between upper anteriors as a sign for good fortune, etc.

\section{Data analysis}

Data was analyzed using SPSS version 15.0 (SPSS, Chicago, IL, USA). Descriptive statistics were obtained and frequency distribution, means, standard deviation were calculated. Positive mean scores of all the questions were calculated using student's $t$ and One-way ANOVA test at $\mathrm{p}$ value $<0.05$. Pearson's correlation coefficient was used to assess the relation of education level and cultural taboos and beliefs regarding dentistry.

\section{Results}

The total sample was 1,664 , which was assorted according to gender, geographical area, and age to know the taboos regarding dental health. (Table 1) shows that most of the participants $(65.3 \%)$ think that after cleaning, teeth get loosen. Half of our respondents believe that extraction of upper teeth affects eye sight. Nearly $74 \%$ of our subjects believe that there is no need to visit a dentist until all the permanent teeth of children erupt. When it was asked about spacing between upper anterior teeth as an indication for good fortune, less than $50 \%$ subjects gave correct response. Overall half of the subjects gave optimistic response regarding proper brushing habits. Most of them were not having the proper knowledge regarding adverse oral habits. Around $76 \%$ of the people said that it is better to have artificial teeth than to repair one's original teeth and some consider that female dentists will not treat the teeth as finely as a male dentist. More than $50 \%$ said that only white teeth are stronger than their counter parts. Approximately $30 \%$ of the participants persist in believing that diseases of oral cavity (like carcinomas) are due to past sins.

Table I Questions for assessing knowledge regarding Cultural beliefs and taboos in dentistry among Indian population

\begin{tabular}{|c|c|c|}
\hline \multirow{2}{*}{ Questions } & \multicolumn{2}{|c|}{ Response } \\
\hline & (Yes) \% & (No)\% \\
\hline I. Do teeth become loose after cleaning? & $65.3 \%$ & $34.7 \%$ \\
\hline 2. Do you think extraction of upper teeth potentially affects eyesight? & $49.6 \%$ & $50.4 \%$ \\
\hline 3. Do you think there is no need to visit dentist before all the primary (milk) teeth have appeared? & $57.6 \%$ & $42.4 \%$ \\
\hline $\begin{array}{l}\text { 4. Do you think there is no need to visit dentist for treating milk teeth, and how they are going to } \\
\text { shed off? }\end{array}$ & $73.8 \%$ & $26.2 \%$ \\
\hline 5. Is there a need of regular dental check up even if there is no problem? & $66.8 \%$ & $33.2 \%$ \\
\hline 6. Do you think spacing between teeth is a sign of good luck? & $45.9 \%$ & $54.1 \%$ \\
\hline 7. Do you think cleaning teeth with fingers is better than with Brush? & $46.6 \%$ & $53.4 \%$ \\
\hline 8. Do you think hard brush cleans your teeth more appropriately than soft brush? & $53.2 \%$ & $46.8 \%$ \\
\hline 9. Do you think Cloves and supari should be used to ease tooth pain? & $57.8 \%$ & $42.2 \%$ \\
\hline $\begin{array}{l}\text { 10. Do you think Charcoal, salt, rice husk, tobacco, etc, in powder form is better than toothpaste in } \\
\text { cleaning teeth? }\end{array}$ & $70.7 \%$ & $29.3 \%$ \\
\hline I I. Do you think when the gums bleed, it is better not to brush the teeth? & $58.4 \%$ & $41.6 \%$ \\
\hline 12. Do you think it is better to have artificial teeth than to repair one's original teeth? & $76.1 \%$ & $23.9 \%$ \\
\hline 13. Do you think female dentist will treat your teeth as finely as a male dentist? & $67.9 \%$ & $32.1 \%$ \\
\hline 14. Do you think only white teeth are stronger? & $57.2 \%$ & $42.8 \%$ \\
\hline I5. Do you think taking medicine while fasting is correct? & $46.3 \%$ & $57.7 \%$ \\
\hline \multicolumn{3}{|l|}{ 16. According to you diseases of oral cavity like oral cancer is mainly caused by: } \\
\hline a. Tobacco chewing \& Smoking, Alcohol (Yes) & $70.9 \%$ & $29.1 \%$ \\
\hline b. God's punishment/ Past sins (No) & & \\
\hline
\end{tabular}


A greater portion of rural people have cultural beliefs and taboos related to dentistry as compared to urban people $(\mathrm{P}<0.05)$. Similarly, a significant gender difference was observed, with females having lower mean scores regarding cultural beliefs and taboos in dentistry compared to males $(\mathrm{P}<0.05)$ (Table 2$)$.

It was found that older age groups have more taboos regarding oral health than younger ones $(\mathrm{P}<0.05)$ as illustrated in (Table 3$)$. Among all the participants, we found a positive linear correlation between educational level and cultural beliefs \& taboos in dentistry (Pearson correlation, $\mathrm{r}=0.537, \mathrm{P}=0.01$ ).

Table 2 Cultural beliefs and taboos in dentistry among Indian population according to geographic area and gender

\begin{tabular}{lllll}
$\begin{array}{l}\text { Geographical } \\
\text { area }\end{array}$ & Number & Mean & SD & p - value \\
\hline Urban & 706 & 10.69 & 2.925 & \\
Rural & 958 & 9.25 & 3.351 & $0.003^{*}$ \\
Gender & & & & \\
Male & 895 & 9.92 & 2.899 & \\
Female & 769 & 9.31 & 3.347 & $0.000^{*}$ \\
\hline
\end{tabular}

Table 3 Cultural beliefs and taboos in dentistry among Indian population according to age groups

\begin{tabular}{lllll}
\hline $\begin{array}{l}\text { Age groups } \\
\text { (years) }\end{array}$ & No. & Mean & SD & p-value \\
\hline $18-29$ & 538 & 6.73 & 2.517 & \\
$30-39$ & 305 & 8.16 & 2.715 & \\
$40-49$ & 266 & 9.91 & 3.298 & $0.000^{*}$ \\
$50-59$ & 338 & 10.14 & 2.902 & \\
$60 \&$ above & 217 & 11.33 & 2.274 & \\
Total & 1664 & 9.64 & 3.128 & \\
\hline
\end{tabular}

\section{Discussion}

India is a land of villages. Out of every 1000 people, 742 live in villages (as per 2001 census). India is a vast country with a varied ethnic, socio-economic and geographical background..$^{10}$ To address the fact that no study exists regarding cultural beliefs and taboos related to dentistry, we conducted this study.

Every culture has its own customs, some of which have a profound influence on incidence of disease. ${ }^{11}{ }^{12}$ In the present study, the individual who lives in an urban area possesses a higher educational level or who are from younger age groups are significantly more apt to take preventive dental actions regardless of cultural beliefs and taboos. These findings were similar to study conducted by Chen MS et al. ${ }^{13}$ among American families.

It was found that overall $65.3 \%$ of the respondents think that after oral prophylaxis teeth will loosen, this may be attributed to the fact that many people from rural areas have little knowledge about dental treatments. They tend to visit the dentist at advanced stages of disease, and at that time, if a dentist removes calculus it may be likely that the tooth will become more mobile. This loosening could lead the patient to consider the dentist as the culprit ${ }^{1}$.
Around half of the respondents believe that extraction of upper teeth deleteriously affects eye sight. For example, extractions performed on older patients, leading to weakening of eye sight due to its vicinity in maxilla, are mere coincidental, but still remain a taboo, hence people relate to this.

It was found that still $57.6 \%$ of study subjects believe that there is no need to go to dentist until all the permanent teeth of child erupts. They think that these teeth are going to shed, so treating them as wastes money and time. This conclusion was determined by comparing the response to the questions number three and four. It was further observed that cultural factors are also deeply involved in matters of personal hygiene, nutrition, immunization and seeking medical care etc. ${ }^{14}$

More than $30 \%$ of participants think that there is no need of a regular dental check-up because dental diseases are not life threatening and can be taken care of with routine medicines available through local pharmacy without consultation of dental surgeon. Some people are quite poor who cannot afford high cost dental treatments. ${ }^{15}$

In India, people consider that spacing between teeth is an indication for good destiny. It is one of the cultural beliefs that are transmitted from one generation to another through learning processes, formal and informal. ${ }^{16}$ In the present study, $50 \%$ of the subjects still do not have appropriate brushing habits, which may be due to poor education. Many people in the countryside use twigs of neem tree as a tooth brush; some use ashes; and some charcoal. The educated and those who have come in contact with urban life use tooth brushes. ${ }^{17}$

In the $21^{\text {st }}$ century more than $50 \%$ the participants still depend on the cultural beliefs and taboos in curing their dental health problems. It may be attributed to the fact that the products like clove are easily available and relieve pain quickly and cleaning materials like charcoal are cost effective that are mostly used in developing countries like India. However, in some countries habits of cola and Khat chewing are widely prevalent. The cola has tannin and caffeine that facilitates healing of oral mucosal lesions but both of them causes dry mouth, thirst, pain, and clicking in the TMJ region. ${ }^{18}$

Most of the subjects think it is better to have artificial set of teeth than to repair the original ones. It may be because of multiple visits for dental treatments and also there is no appointment of dentist at primary health centre level in India. Nearly $46 \%$ assume that taking medicine during fasting is correct as in our country it is one of the important taboo and is equally acceptable both in urban as well as rural areas e.g. fasting which may have deleterious impact on health and oral health. When it was asked regarding diseases of oral cavity like cancer, still some people believe that these are due to wrath of gods and goddesses and administration of drugs is still considered harmful for treatment. ${ }^{19}$ Whatever may be the reasons for these cultural beliefs and taboos, they definitely have harmful effects on the oral tissues and hence have to be discouraged. So, dental professionals along with primary health workers and school teachers can a play a vital role in creating the awareness and to remove the misconceptions that hinder an individual from seeking dental services.

\section{Conclusion}

The study revealed poor knowledge, attitude and practices regarding dentistry in India, and the deficit is greater in rural areas in 
all aspects. Therefore, area of residence, especially in countries like India where the majority of the population resides in rural regions, should be considered in tailoring communicative strategies and designing future interventions.

\section{Funding details}

None.

\section{Acknowledgments}

None.

\section{Conflicts of interest}

The authors declare that there is no conflict of interest.

\section{References}

1. Park K. Social sciences and medicine. Park's textbook of preventive and social medicine. 17th ed. M/ s Banarsidas Bhanot publishers; 2002. 440-451 p.

2. Bhasin V. Medical Anthropology: A Review. Ethno-Med. 2007;1(1):1-20.

3. Kushwah SS. Public health learning and practice from hygiene to community medicine, health management and beyond issues: Challenges and options. Indian Journal of Community Medicine. 2007;32(2):103107.

4. Patil R, Mittal A, Vedapriya DR, Khan MI, et al. Taboos and misconceptions about food during pregnancy among rural population of Pondicherry. Calicut Medical Journal. 2010;8(2):105.

5. Goldsmid JM, Speare R, Bettiol SS. The parasitology of foods. In: Foodborne Microorganisms of Public Health Significance. $6^{\text {th }}$ ed. Hocking. Waterloo: AIFST; 2002.

6. Chu MP. Chinese Cultural Taboos That Affect Their Language \& Behavior Choices. Asian Culture and History. 2009;1(2):122-139.
7. Kalipeni E, Mbugua N. A review of preventative efforts in the fight against HIV and AIDS in Africa. Norsk Geografisk Tidsskrift-Norwegian Journal of Geography. 2005;59(1):26-36.

8. Carr Hill R, Katabaro KJ, Katahoire AR, et al. The impact of HIV/AIDS on education and institutionalizing preventive education. International Institute for educational planning. 2002.

9. Lim LP, Schwarz E, Lo ECM. Chinese health beliefs and oral health practices among the middle-aged and the elderly in Hong Kong. Community Dent Oral Epidemiol. 1994;22(5):364-368.

10. Singh P, Arora V. Military Dentistry: Terrain, Trends and Training. $1^{\text {st }}$ edn. New Delhi: Jaypee Brothers Medical Publishers; 2005. 276 p.

11. AM Dunn. Culture Competence and the Primary Care Provider. J Pediatr Health Care. 2002;16(3):105-111.

12. Majumdar DN, Madan TN. An introduction to social Anthropology. Asia Publication House Bombay; 1956.

13. Chen MS, Stone DB. Toothbrushing, flossing, and dental visits in relation to socioeconomic characteristics of white American families. Community Dent Oral Epidemiol. 1983;11(6):325-332.

14. Chandra Shekar BR, Raja Babu P. Cultural factors in Health and Oral health. Indian Journal of Dental Advancements. 2009;1:24-30.

15. Kiyak HA. Recent Advances in Behavioral Research in Geriatric Dentistry. Gerodontology. 1988;7(1):27-36.

16. Dandrad RG. The Cultural Part of Cognition. Cognitive science. 1981;5(3):179-195.

17. Vani G, M Ganesh Babu, Panchanatham N. Toothpaste Products Analysis of Consumer Behavior in Bangalore City. Journal of Economics and Behavioral Studies. 2010;1(1):27-39.

18. Prabhu SR. Oral diseases in the tropics. Oxford, New York: Oxford University Press; 1992. 794 p.

19. World Health Organization. WHO Chronicle. 1976;3:337-339. 